\title{
Toolkit for Web Development Based on Web Based Information System
}

\author{
Prince Singha $^{1 *}$, Aditya ${ }^{2}$, Kunal Dubey $^{3}$, Jagadeeswararao Palli $^{4}$ \\ ${ }^{1}$ Computer Science \& Engineering, SRM Institute of Science \& Technology, Chennai, India \\ ${ }^{2}$ Computer Science \& Engineering, SRM Institute of Science \& Technology, Chennai, India \\ ${ }^{3}$ Computer Science \& Engineering, SRM Institute of Science \& Technology, Chennai, India \\ ${ }^{4}$ Computer Science \& Engineering, SRM Institute of Science \& Technology, Chennai, India
}

Corresponding Author: princesingha007@gmail.com, Phone.: 7550177086

Available online at: www.isroset.org

Received: 06/Oct/ 2018, Accepted: 22/Oct/ 2018, Online: 31/Oct/2018

\begin{abstract}
This paper intends to exhibit the social and authoritative parts of electronic data frameworks. Presently we are in the 21 st century and two decades will be finished soon. A century ago has been considered as the ascending of Information and correspondence innovation. These days there is expanding advancement of online data frameworks for social and hierarchical divisions Electronic data frameworks in light of web innovations which shares distinctive kinds of Internet convention and assumes an essential part to gather, putting away, gathering and imparting information from various sources and spread data initially. The speed and productivity of electronic data framework which incorporates both neighborhood and worldwide systems, databases and diverse sorts of program for data preparing makes social and hierarchical life less demanding for individuals. The online applications keep up activities of administration. Such applications incorporates quality administration forms, life cycle of authoritative objective, actualizing and sharing creation plan This electronic innovation affects social connection, social conduct and different association issues.
\end{abstract}

Keywords-Web Development, Electronic Data Framework, Speed, Productivity.

\section{INTRODUCTION}

Data innovation is assuming a critical part in the advancement of present-day society and social life. It has changed the entire world into a worldwide town. Presently social life has moved to on the web. Individuals are utilizing the dialog board, online journals, and person to person communication destinations through electronic innovation to impart carefully. Internet, advanced library, online business, and PC based separation learning has made our life less demanding. These days individuals are ending up more keen on online networks to share interests and exercises. The greater part of the interpersonal organization administrations are online and these locales are furnishing diverse approaches to associate with others, for example, texting and email. More finished WBIS can be utilized from numerous points of view in our social life, for example, instructive foundations, new and media associations, taxpayer driven organizations and so forth.

Business associations are utilizing this WBIS to build up their business and to maintain their business comprehensively. Business associations can choose the different scope of an item from the item database. That innovation tells the associations the value rundown of the item and they can arrange different items on the web. So it fills in as a purchasing and offering media everywhere throughout the world. The associations can track requests and refresh the data through the web. Also, these days all the multinational business associations are utilizing the electronic data framework to keep up a correspondence with different branches. So this innovation is assuming a critical part of business improvement.

\section{KEY FEATURES}

\section{A. Cross stage similarity}

Most electronic applications are good in unexpected stages in comparison to conventional introduced programming. The base necessity would be an internet browser (Internet Explorer, Firefox, Netscape and so on.). You can utilize distinctive OS, for example, Windows, Linux or Mac to run the web applications.

\section{B. More Manageable}

WBIS just should be introduced on the server setting insignificant prerequisites on the end client workstation, which makes the framework less demanding to keep up and refresh as for the most part it should all be possible on the server. 


\section{Various simultaneous clients}

Online applications can to be sure be utilized by numerous clients in the meantime. It's not important to share screen or send a screen capture when numerous clients see and even alter a similar report in the meantime. Web conferencing and online coordinated effort organizations direct some key changes and clients just investigate what they truly need to work adequately and co-alter records together.

\section{Decreased cost:}

Online applications can diminish cost because of help and support, bring down necessities on the end client framework and streamlined engineering. It doesn't require any appropriation or promoting framework.

\section{E. Secure live information:}

These applications can diminish the danger of losing information because of an unforeseen circle crash or PC infection. Organizations of electronic applications give broad information reinforcement benefit either as a basic part or essential administration or in some cases as a paid administration.

\section{SOCIAL PARTS OF ELECTRONIC DATA FRAMEWORK}

In the perspective of Karl Marx, individuals are characteristically, fundamentally and by definition social creatures who - past being "gregarious animals" - can't survive and address their issues other than through social coactivity and affiliation. Their social qualities are in this manner to a substantial degree an impartially given reality, stamped on them from birth and attested by socialization forms; and, as indicated by Marx, in delivering and repeating their material life, individuals should fundamentally go into relations of generation which are "free of their will".

\section{EXISTING FRAMEWORK}

The ongoing toolboxs are accessible on website pages so without web nobody can get to those pages so we will make windows application base Html-Tool compartment so we can utilize this in any windows based screen and can influence a dynamic web to page which causes you to incorporate both CSS template and java s4cript capacities .

\section{A. Disservices of Existing Framework:}

Predominant culture - while data innovation may have made the world a worldwide town, it has likewise added to one culture overwhelming another weaker one. For instance it is currently contended that US impacts how most youthful young people everywhere throughout the world presently act, dress and carry on. Dialects too have moved toward becoming eclipsed, with English turning into the essential method of correspondence for business and everything else.

Security issues - cheats and programmers gain admittance to characters and corporate saboteurs target delicate organization information. Such information can incorporate merchant data, bank records, protected innovation and individual information on organization administration. The programmers circulate the data over the Web, pitch it to match organizations or utilize it to harm the organization's picture. For instance, a few retail chains were focused on as of late by programmers who stole client data from their data frameworks and disseminated Government disability numbers and Mastercard information over the Web.

Usage costs - to coordinate the data framework it require truly great measure of cost for a situation of programming, equipment and individuals. Programming, equipment and some different administrations ought to be leased, purchased and upheld. Representatives should be prepared with new data innovation and programming.

\section{Proposed FrameWORK}

We propose Web advancement instruments permit web engineers to test and troubleshoot their code. They are not quite the same as web designers and coordinated advancement situations (IDEs) in that they don't aid the immediate making of a page, rather they are instruments utilized for testing the UI of a site or web application.

Web advancement instruments come as program additional items or implicit highlights in internet browsers. The most well known internet browsers today, Google Chrome, Firefox, Musical show, Web Wayfarer, UC program and Safari, have worked in instruments to help web engineers, and numerous extra additional items can be found in their individual module download focuses.

Web advancement instruments enable engineers to work with an assortment of web innovations, including HTML, CSS, the DOM, JavaScript, and different parts that are taken care of by the internet browser. Because of expanding request from internet browsers to accomplish progressively, well known internet browsers have included more highlights designed for engineers.

\section{A. Favorable circumstances of Proposed Framework:}

Unwavering quality

Broad research writing and an accumulation of business devices have been committed to testing, guaranteeing, guaranteeing, and estimating programming unwavering quality. Wellbeing basic programming applications, for example, broadcast communications, aviation, and therapeutic gadgets request profoundly dependable programming, yet albeit numerous analysts are hesitant to let it be known, most programming right now delivered does not 
should be exceedingly solid. Numerous organizations' business achievement relies upon Web programming, anyway - if the product does not work dependably, the organizations won't succeed. The client base for Web programming is vast and anticipates that Internet applications will fill in as dependably as though they were setting off to the supermarket or calling to arrange from an inventory. In addition, if an Internet application does not function admirably, the clients don't need to drive further to achieve another store; they can essentially indicate their program an alternate URL. Sites that rely upon temperamental programming will lose clients, and the organizations could lose much cash. Organizations that need to work together finished the Internet must spend assets to guarantee high unwavering quality. Surely, they can't bear the cost of not to.

\section{Ease of use}

Web application clients have developed to expect simple Web exchanges - as straightforward as purchasing an item at a store. Albeit much insight exists on the best way to create usable programming and Sites, many Sites still don't meet most clients' ease of use desires. This, combined with the way that clients display little website reliability, implies unusable Sites won't be utilized - clients will change to more usable Sites when they come on the web.

\section{Security}

We have all caught wind of Sites being broken and private client data disseminated or held for recover. This is just a single case of the numerous potential security imperfections in Web programming applications. At the point when the Internet worked basically to disseminate online handouts, security breaks had generally little outcomes. Today, be that as it may, the break of an organization's Site can cause noteworthy income misfortunes, huge repair costs, lawful results, and loss of validity with clients. Web programming applications should in this manner handle client information and other electronic data as safely as could be expected under the circumstances. Programming security is one of the quickest developing examination territories in software engineering, however Web programming designers right now confront a colossal setback in both accessible learning and talented faculty.

\section{Accessibility}

In our grandparents' chance, if a businessperson in a residential area needed to take a meal break, he would basically put a sign on the front entryway that said "back at 1:00." Albeit the present clients hope to have the capacity to shop amid noon, we don't anticipate that stores will be open after $12 \mathrm{pm}$ or on siestas. Online, clients not just expect accessibility 24 hours per day, seven days seven days, they anticipate that the Site will be operational each day of the year-"all day, every day/365." Accessibility implies something beyond being up and running day in and day out/365; the Internet programming must likewise be open to differing programs. In the apparently endless program wars of the previous couple of years, some product sellers effectively tried to ensure their product would not work under contenders' programs. By utilizing highlights accessible for one program or on one stage, Web programming designers progress toward becoming "troopers" in the program wars, here and there accidentally. To be accessible in this sense, Sites must adjust their introductions to work with all programs, which requires altogether more information and exertion on engineers' part.

\section{Versatility}

We should build Web programming applications to have the capacity to develop rapidly as far as both what number of clients they can administration and what number of administrations they can offer. The requirement for adaptability has driven numerous innovation advancements of the previous couple of years. The business has grown new programming dialects, outline techniques, and correspondence and information move conventions in huge part to permit Sites to develop as required. Adaptability additionally specifically impacts different properties. Any programming educator realizes that any plan will work for little classroom works out, however substantial programming applications require teach and imagination. Similarly, as Sites develop, little programming shortcomings that had no underlying detectable impacts can prompt disappointments (unwavering quality issues), ease of use issues, and security breaks. Planning and building Web programming applications that scale well speaks to one of the present most fascinating and essential programming advancement challenges.

\section{Viability}

One novel part of Online programming frameworks is the recurrence of new discharges. Customary programming includes showcasing, deals, and sending or even close to home establishment at clients' locales. Since this procedure is costly, programming producers generally gather upkeep alterations after some time and convey them to clients all the while. For a product item discharged today, engineers will begin gathering a rundown of fundamental changes. For a basic change, (say, changing a catch's name), the adjustment may be made promptly. In any case, the deferral in discharges implies that clients won't get more mind boggling (and likely critical) alterations for a considerable length of time, maybe years. Online programming, be that as it may, gives clients quick access to support refreshes - both little changes, (for example, changing the mark on a catch) and basic overhauls can be introduced instantly. Rather than upkeep cycles of months or years, Sites can have support cycles of days or even hours. Albeit other programming applications have high upkeep prerequisites, and some exploration has concentrated "on-the-fly" support for 
particular applications, visit support has at no other time been essential for such an amount of business programming. Another implication of the expanded refresh rate needs to do with similarity. Clients don't generally update their product; consequently, programming sellers must guarantee similarity amongst new and old forms. Organizations can control the dissemination of Web programming to kill that need, however Web applications should in any case have the capacity to run effectively on a few Internet browsers and numerous renditions of every program. Another conceivable outcome of the quick refresh rate is that designers may not feel a similar need to settle blames before discharge - they can simply be settled later.

\section{MOdUleS}

1. Html Editorial manager Module.

2. Html with Css Editorial manager Module.

3. Html with Css and Js Editorial manager Module.

\section{A. Modules Description:}

Html Manager :

In this module, we are outlining the static page by utilizing the Html Proofreader and going to make all the make all the required content fields and marks for the website page .

\section{Html with Css Editorial manager:}

In this module, we have we are planning the site page by utilizing the Html Editorial manager with Css which incorporates the styles for the website page .

\section{Html with Css \& Js Editorial manager:}

In this module, we have we are planning the site page by utilizing the Html Editorial manager with Css\&Js which incorporates the styles and content capacities for the website page which influences the web to page to progressively and female horse receptive to the customer .

\section{SYSTEM CONFIGURATION}

Equipment Design

$\begin{array}{ll}\text { Processor- } & \text { Pentium - IV } \\ \text { Speed }- & 1.1 \mathrm{Ghz} \\ \text { RAM } & 256 \mathrm{MB}(\mathrm{min}) \\ \text { Hard Disk - } & \text { 20GB } \\ & \\ \text { Programming Design } & \quad \text { : WindowsXP } \\ \text { Operating System } & \text { : JAVA }\end{array}$

Accomplishing the amazing necessities of Web programming speaks to a troublesome test. Albeit different portions of the product business have effectively aced a portion of these, for example, the requirement for dependability in media communications and system directing, aviation, and therapeutic gadgets, they have ordinarily done as such by enlisting the specific best designers available, utilizing bunches of assets (time, engineers, and testing), or depending on old, stable programming and advancements. Sadly, these arrangements won't work for Web applications. There are basically insufficient of the "best engineers" to actualize the majority of the Internet programming required today, and few however the biggest organizations can bear to put additional assets as time, designers, and testing. At long last, it ought to be evident that old, stable programming innovations won't get the job done as a base for the Internet it depends on the most recent front line programming innovation. In spite of the fact that the utilization of new innovation includes some hazard, it enables us to accomplish generally unattainable levels of versatility and practicality.

Past Web quality research has concentrated on general portrayal of some particular parts of Web quality and gave careful consideration to build distinguishing proof and estimation endeavors. In this investigation, we moved past expressive and story proof to observational assessment and check by building up a multidimensional scale for estimating client saw Web quality. The aftereffects of the two-staged examination revealed four measurements of saw Web quality (specialized sufficiency, particular substance, content quality, and appearance) and gave confirmation to the psychometric properties of the 25-thing instrument. Another commitment is that while past Web quality research centers for the most part around the points of view of Web engineers and originators, the ebb and flow ponder focuses Online clients. In this period of extraordinary rivalry and client responsiveness, the clients are real partners and ought not be overlooked. The impediments of the examination incorporate those generally connected with instrument-building and study strategies. Be that as it may, the broad testing and approval enhanced the interior legitimacy, and utilizing a few gatherings of subjects enhanced the outer legitimacy and generalizability of the instrument to a bigger

populace. All things considered, instruments are constantly subject to facilitate change and we urge individual specialists to do as such. The Internet quality model/instrument has viable and in addition hypothetical and research applications. As far as down to earth applications, an approved instrument gives a vital apparatus to surveying the nature of Site. The Web is facilitating countless Sites fluctuating generally as far as quality. The scales may be utilized to evaluate the nature of a given Site. This could be done at the general quality level utilizing the 25-thing instrument or at a particular 
quality measurement level, e.g. utilizing a sub-size of one of the four measurements of saw Web quality. This assessment may give a quick and early criticism to the firm. On the off chance that the firm ends up ailing in any of the measurements, at that point it might complete a more nitty gritty investigation and take important restorative activities. The four measurements and the 25-things of the instrument may likewise be utilized by Web specialists in a proactive way. The measurements and the things might be considered unequivocally in the site plan. Also, a firm might need to survey the relative significance of the four quality measurements and the particular things in its own particular setting. While this investigation gave their relative significance in light of its own example, each firm is special in view of its items, administrations, clients, business techniques, and so on. Such an assessment would encourage the plan of a quality Site in any case.

\section{REFERENCES}

[1] Boyd, Danah; Ellison, Nicole (2007). "Social Network Sites: Definition, History and Scholarship. Journal of ComputerMediated Communication.

[2] Eric Gleave, Howard T. Welser, Tomas M. Lento, Marc A. Smith 'A conceptual and operational definition of social role in online community'-Proceedings of the 42nd Hawaii International conference on system science-2009.

[3] Gianluca, Zanutto and Alberto, D.T "Web-based information success: A measurement model of acceptance and fit.

[4] Linda Askenas and Alf westelius (2003) 'Five roles of an information system: A social constructionist approach of analysing the use of ERP system, journal vol3.

[5] Nabil Adam and Yelena Yesha, eds, Electronic Commerce: Current Research Issues and Applications, Springer, 1996

[6] Morrison, Ken; Marx, Durkheim, Weber (2006). " Formations of modern social thought.

\section{Authors Profile}

Mr. Prince Singha is a prefinal year engineering student of SRM Institute of Science \& Technology, Chennai, currently pursuing B.Tech degree in Computer Science \& Engineering.

. Mr. Aditya is a prefinal year engineering student of SRM Institute of Science \& Technology, Chennai, currently pursuing B.Tech degree in Computer Science \& Engineering.

Mr. Kunal Dubey is a prefinal year engineering student of SRM Institute of Science \& Technology, Chennai, currently pursuing B.Tech degree in Computer Science \& Engineering.

Mr. Jagadeeswararao Palli is a prefinal year engineering student of SRM Institute of Science \& Technology, Chennai, currently pursuing B.Tech degree in Computer Science \& Engineering. 